Int. J. Dev. Biol. 48: 805-817 (2004)

doi: $10.1387 / \mathrm{ijdb} .041863 \mathrm{hr}$

\title{
Lens differentiation and crystallin regulation: a chick model
}

\author{
HASAN M. REZA and KUNIO YASUDA* \\ Graduate School of Biological Sciences, Nara Institute of Science and Technology (Grad. Schl. Biol. Sci., NAIST), Takayama, Ikoma, Nara, \\ JAPAN
}

\begin{abstract}
The vertebrate lens is a transparent polarized tissue that acts as the gateway for vision. The chick lens is an excellent model for studying tissue organogenesis, since it is both accessible and easily manipulated during embryonic stages. The chick lens consists of two morphologically discrete compartments, the epithelium and the fiber-cell mass. Evidence indicates that the early phases of lens development involve several sequential events, including tissue interactions, cell proliferation and differentiation. The morphological change during lens development is associated with the concurrent and distinct functions of numerous transcription factors. Diffusible molecules from the complementary neural tissue play vital roles during the entire process of lens development. Lens tissue is characterized by the ample production of crystallins, lens specific proteins which provide structural integrity and functional properties to the lens. Thus, the study of crystallin regulation should provide insight into the development of a functional lens during embryogenesis. This process has been shown to involve a complex and evolutionary conserved pathway supported by different regulatory proteins.
\end{abstract}

KEY WORDS: lens differentiation, transcription factor, crystallin, chick

\section{Introduction}

The eye is considered ideal for studying the embryonic development of an organ. In particular, developmental biologists have focused on the lens to attempt to uncover general mechanisms underlying embryonic induction (Jacobson and Sater, 1988; Gehring and Ikeo, 1999). Due to the ease of manipulation of lens tissues, cellular interactions can be easily elucidated in this model system.

Embryonic lens arises from the competent head ectoderm, which is able to respond to signals from the optic vesicle. In response to these inductive signals, a specific portion of the head ectoderm, located opposite the protruding primary optic vesicle, undergoes cell proliferation and thickening (Henry and Grainger, 1990; Fig.1). These cells, which constitute the lens placode, assume a characteristic shape and orientation, lying in an invaginating stripe that forms the circular lens vesicle. During the formation of the lens vesicle, the primary optic vesicle, which acts as a source of lens inductive signals, also invaginates, forming the optic cup. The optic cup completely surrounds the primary lens vesicle, except for the anterior side (Fig. 1). The epithelial cells in the anterior portion of the lens vesicle form a monolayer covering the anterior surface, while posterior cells leave the cell cycle and form primary fiber cells. The elongating young fiber cells reside at the equatorial region, whereas mature fiber cells, which are characterized by the loss of their nuclei, occupy the central region of the lens.
The 'bow region' of a developing lens serves as a 'dynamic state', where morphological change is evident through the transition from lens epithelium to lens fiber cells. Such differentiation of lens fiber cells depends on several secreted factors, including fibroblast growth factors (FGF), Wingless and TGF $\beta$ proteins, which regulate many differentiation factors and/or cell-cycle regulators during lens formation.

All morphological changes of the lens, from induction to maturation, are characterized by the expression of different sets of genes whose functions are distinct and essential for proper lens development. Crystallins are the major water soluble structural proteins in the lens (Cvekl and Piatigorsky, 1996; Bhat, 2003). Crystallin synthesis serves as a conclusive indication of lens development, confirming the occurrence of all possible interactions required for lens formation.

\section{Lens induction: a merger of primitive and modern per- spectives}

Lens development is a multi-step process that involves a complex series of interactions between two different cell populations: ectodermally derived presumptive lens ectoderm (PLE) and

Abbreviations used in this paper: BMP, bone morphogenetic protein; FGF, fibroblast growth factor; PLE, presumptive lens ectoderm.

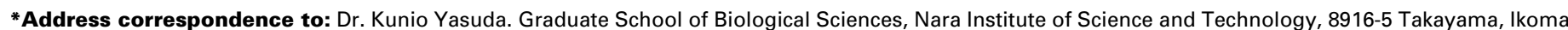
630-0101, JAPAN. Fax: +81-743-72-5559. e-mail: kyasuda@bs.aist-nara.ac.jp
} 
neurally derived optic vesicle. The remarkable observations made by Spemann and Lewis from two separate sets of experiments in frogs independently showed that the presence of optic vesicle is essential for lens formation, presumably by providing inducing effects to the head ectoderm to generate lens (Spemann, 1901; Lewis, 1904). Spemann observed loss of lens when he mechanically ablated the retina primordium of the anterior neural plate in Rana fusca, whereas Lewis showed ectopic lens formation when he transplanted optic vesicles under the flank ectoderm in Rana palustris. In contrast, Mencl found a double-headed salmon embryo having two differentiated lenses in the absence of optic cups, and King revealed the presence of lens-like structures in Rana palustris (Mencl, 1903; King, 1905). Subsequently, Spemann observed lens-like structures after ablating the optic vesicle in Rana esculenta, but he was also able to reproduce his previous findings in Rana fusca. Although the debate on this issue still persists among developmental biologists, it may be partly explained by species variation and by the varied experimental conditions, especially the timing of optic cup ablation.

Several observations from studies on Xenopus embryos by Grainger and colleagues have clarified the early events of lens induction (Grainger, 1992; Grainger et al., 1988). These studies showed that lens induction is governed by four successive events resulting from proximate tissue interactions: competence, bias, specification and differentiation (Grainger, 1992). Competence, the ability of head ectoderm to respond to a specific inductive signal, is achieved maximally during the mid-to-late gastrula stage. It was ascertained by showing lens formation after transplanting the ectoderm of mid-to-late gastrula stage into the presumptive lens-forming region of neural plate stage embryos (Servetnick and Grainger, 1991). Bias for lens induction, which is attained by head ectoderm during the neural plate stage, is partly mediated by planar signals from the anterior neural plate (Grainger, 1992; Grainger et al., 1997). Lens specification is the third event that occurs at the neural tube stage, around the time of contact between the biased ectoderm and the optic vesicle (Henry and Grainger, 1990). Differentiation, the final step of lens induction, starts at the time of placode formation and continues throughout the life of the organism (Grainger, 1992). Lens morphology first becomes detectable at the time of formation of the lens placode, by differentiation of the head ectoderm and its subsequent proliferation.

Transcription factors play significant roles in all developmental processes. Several transcription factors have been implicated in different stages of lens formation, and the expression patterns of these factors, along with gain- and loss-of-function experiments, have been studied in various model animals (Kondoh, 1999; Ashery-Padan and Gruss, 2001; Chow and Lang, 2001). In this review, we describe the early events of the lens induction process and the mechanisms underlying crystallin expression during lens development in the chick.

\section{Appearance of lens structure and related gene func- tions}

Morphological evidence of lens formation from the congenital overlying head ectoderm is first apparent with the formation of the thickened lens placode, which follows the physical contact of the anterior side of the neural tube with the head ectoderm. The condition prior to placode formation is the culmination of the specification of the presumptive lens ectoderm, the precise domain of the initial broader ectoderm (Henry and Grainger, 1990; Furuta and Hogan, 1998). The molecular events occurring in these tissues result from the activities of various regulatory proteins.

A growing number of genes have been found essential for the initiation of lens placode formation. Pax 6 is the best studied eyeforming gene among the transcription factors involved in the process of lens induction. Pax6 is known to interact with several upstream factors during lens formation. For example, of those genes identified to date, the Otx2 gene, which encodes a bicoidtype homeodomain protein, is first expressed in the PLE at the midneural plate stage in Xenopus (Zygar et al., 1998). Its expression in the PLE, which is induced by signals from the anterior neural plate, declines at the time of lens placode formation. The finding that expression of Otx 2 in the PLE is followed by Pax6 expression suggests that Otx2 acts upstream of Pax6. Otx2-null mutant embryos die due to a defect in gastrulation prior to eye formation, and Otx2-heterozygous mutant mice show variable phenotypes, including absence of lens, making the precise role of Otx2 in lens development unclear (Acampora et al., 1995; Matsuo et al., 1995; Ang et al., 1996).

In mice, two members of the TALE homeoprotein family, Meis 1 and Meis2, have been recently catalogued as genes that directly regulate Pax6 expression, by acting through a 26bp sequence in the Pax6 lens ectodermal enhancer (Zhang et al., 2002). By analyzing mutants produced by site directed mutagenesis in the 526-bp ectodermal Pax6 lens enhancer element, Meis binding was shown to be essential for Pax6 lens ectoderm activity in vivo. Transgenic experiments revealed that Meis2, but not Meis1, could upregulate ectodermal Pax6 expression in mice, whereas loss-offunction experiments using Meis1-En in chick embryos clearly showed the downregulation of Pax6 (Zhang et al., 2002). Taken together, these results suggest that the Meis proteins regulate Pax6 expression differentially in the lens ectoderm in various species. The identification of five putative Meis binding sites that are clustered in a 200bp sequence within the furthest lens enhancer element of human and mouse Pax6 indicates that Meis proteins probably regulate Pax6 expression in a diverse manner at different time points during the entire process of lens development (Zhang et al., 2002). Although the Meis proteins bind $\mathrm{Pbx}$, a protein that acts as a co-factor in DNA binding, the Meis proteins also require other binding partners, which bind to each side of the Meis site in regulating Pax6 (Chang et al., 1997; Mann and Affolter, 1998; Zhang et al., 2002).

CP2 is a ubiquitously expressed protein that usually interacts with other factors to activate downstream tissue-specific genes (Weintraub et al., 1990; Lassar et al., 1991; Murata et al., 1998). We have observed that misexpression of CP2 results in the ectopic induction of Pax6 mRNA in chick embryos (NS and KY, unpublished data). These results suggest that CP2 may cooperate with the Meis proteins to activate Pax6 during the process of lens induction.

\section{Pax6 in lens placode formation}

Pax6 is a member of the family of developmentally regulated Pax transcription factors. The Pax6 protein consists of a DNAbinding paired domain, a paired-type homeodomain and a carboxyterminal activation domain (Chalepakis et al., 1991; Walther et al., 1991; Glaser et al., 1994). An alternatively spliced form of Pax6, 
containing an insertion of 14 additional amino acid residues in exon 5 , has also been detected in various vertebrates, including humans (Walther and Gruss, 1991; Glaser et al., 1992; Puschel et al., 1992). Both Pax6 isoforms are expressed in the developing lens, retina, brain, and spinal cord, and distinct tissue-specific roles of these proteins have been described (Epstein et al., 1994b; Kozmik et al., 1997; Singh et al., 2002; van Heyningen and Williamson, 2002). Pax6 expression has been detected in the head ectoderm, including the presumptive lens ectoderm and developing optic vesicle, beginning at the earliest stages of development in vertebrates (Walther and Gruss, 1991; Li et al., 1994). In developing chick embryos, the alternative form of Pax6 is expressed at a slightly lower level than the regular form in lens tissue (M.Y and K.Y, unpublished data).

Extensive work has established that PaxG is an essential regulatory gene for eye morphogenesis in both vertebrates and invertebrates (Gehring and Ikeo, 1999). In the chick, Pax6 is first detected at the neural plate stage, an earlier stage than in mice $(\mathrm{Li}$ et al., 1994; Hanson and Van Heyningen, 1995). We have confirmed Pax 6 expression in a broader domain of overlying ectoderm at stage 9 (Fig. 2), clearly indicating the involvement of this protein in the early induction process of the lens. Homozygous Pax6mutants of mice and rats experience the complete loss of both eyes, together with severe cranio-facial abnormalities (Hill et al., 1991; Matsuo etal., 1993; Fujiwara etal., 1994). Co-culture of head ectoderm from wild-type rat embryos with optic vesicles from either wild-type or Pax6-mutant rat (rSey) embryos has been shown to form normal lens structures, but co-culture of head ectoderm from Pax6-mutant rat embryos with wild-type optic vesicles resulted in the absence of lens formation (Fujiwara et al., 1994). Consistently, conditional inactivation of PaxG in the head ectoderm of $L e$ mutant mice resulted in the absence of placode formation, which also supports the cell-autonomous requirement for $\mathrm{Pax} 6$ in placode initiation (Ashery-Padan et al., 2000). In Lemutant mice, Sox2 upregulation confirmed the establishment of specification by the lens ectoderm, but the absence of placode formation suggested that the latter is dependent on Pax6 function in the specified ectoderm.

Absence of lens and optic cup formation has been observed when Pax6 function is inhibited in the ectodermal lens primordium of the chick (Reza et al., 2002). Interestingly, both Pax6 isoforms exhibit very similar functions during early placode-forming stages, as determined by loss-of-function experiments using either variant (Reza et al., 2002). In these embryos, no lens structure was detected, indicating that ectodermal Pax6 expression is essential for lens placode formation. Misexpression of Pax6 was observed to induce ectopic eye formation in Drosophila (Halder et al., 1995) and Xenopus (Chow et al.,
1999), although most of the ectopic lenses were incompletely formed, indicating that, while Pax6 function is important for early placode initiation, subsequent steps also require other factors expressed in the same time frame. We have found that Pax6 is unable to induce any lens structure when misexpressed in different parts of the embryonic lens-forming ectoderm of chick embryos, indicating that Pax6 function is not identical in all species. Indeed, Pax6 is indispensable during the formation of chick lens placode and may function to maintain undifferentiated lens epithelium during later stages of lens development.

In homozygous Pax 6 - and Lemutant mice, several genes implicated in lens induction, including Sox2, Six3 and Prox1, are down-regulated (Ashery-Padan and Gruss, 2001). In contrast, in ovo electroporation of dominant-negative Pax6 into the lens primordium of stage 10 chick embryos did not downregulate the expression of Sox2 and Six3 (Reza et al., 2002). This discrepancy in the control of downstream genes by Pax6 may be due to interspecific variation. The differential expression pattern of Sox2 and Six3 in these two species suggests that upstream regulatory factors of Pax 6 are not identical in the two species, or that they exert common, but not identical, effects. Notably, in the mouse, Sox2 expression is upregulated at the time of placode formation and remains extremely high in all cells of the invaginating placode, whereas, in the chick, Sox2 expression is present at a moderate level in all of these cells (Kamachi et al., 1998; Reza et al., 2002). The expression patterns of Six3 in mice and chicks are even more distinctive. In the mouse, Six 3 is highly expressed in all cells of the invaginating lens, whereas, in the chick, Six3 expression is localized to the tip of the closing lens, while the inner cells of the

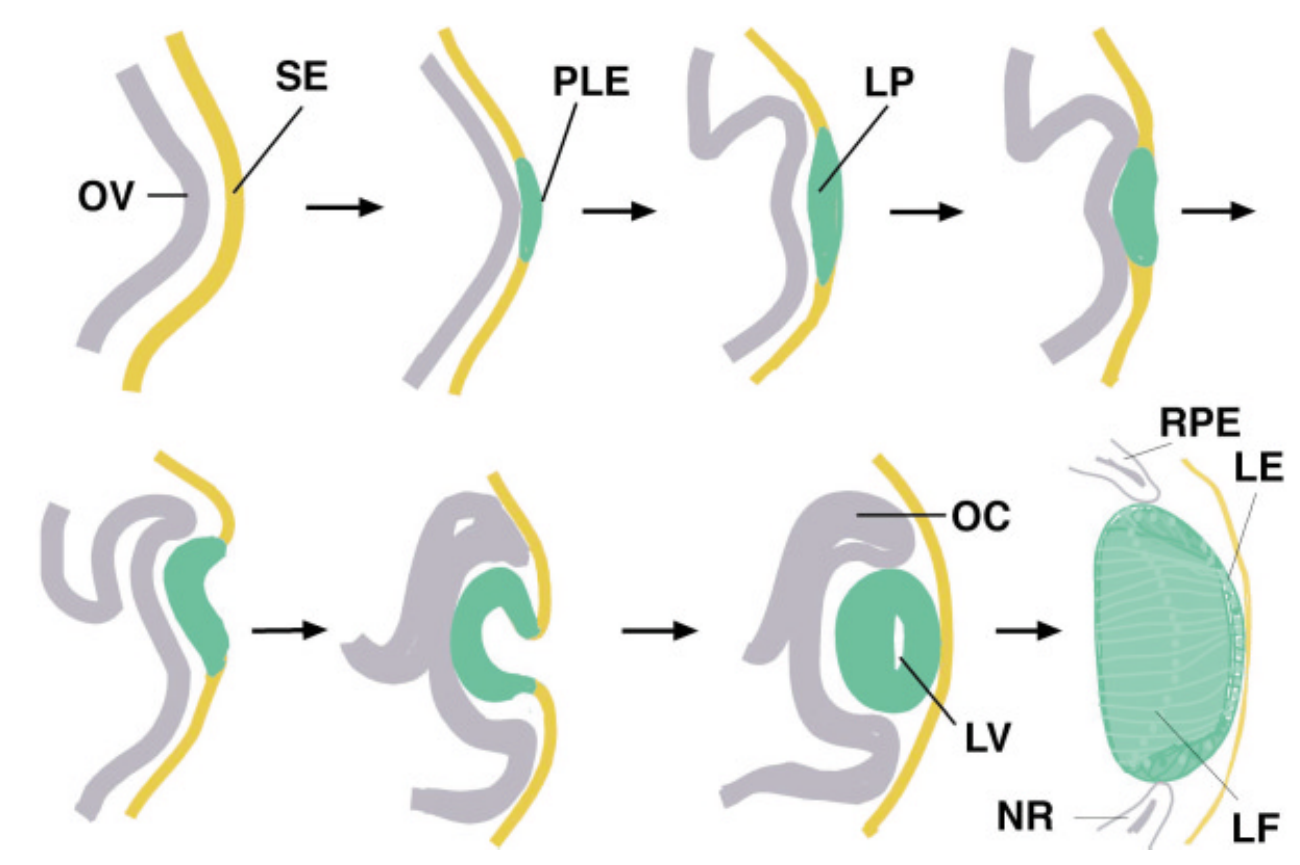

Fig. 1. Schematic representation of vertebrate lens development. Gray represents retina lineage, green represents lens lineage and yellow indicates ectodermal tissue other than lens structure. Arrows show the direction of the successive stages of endogenous lens formation. OV, optic vesicle; SE, surface ectoderm; $P L E$, presumptive lens ectoderm; $L P$, lens placode; $O C$, optic cup; $L V$, lens vesicle; $L F$, lens fiber; $L E$, lens epithelium; NR, neural retina; $R P E$, retinal pigment epithelium. 
Pax6

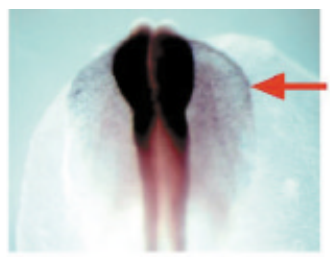

Sox2
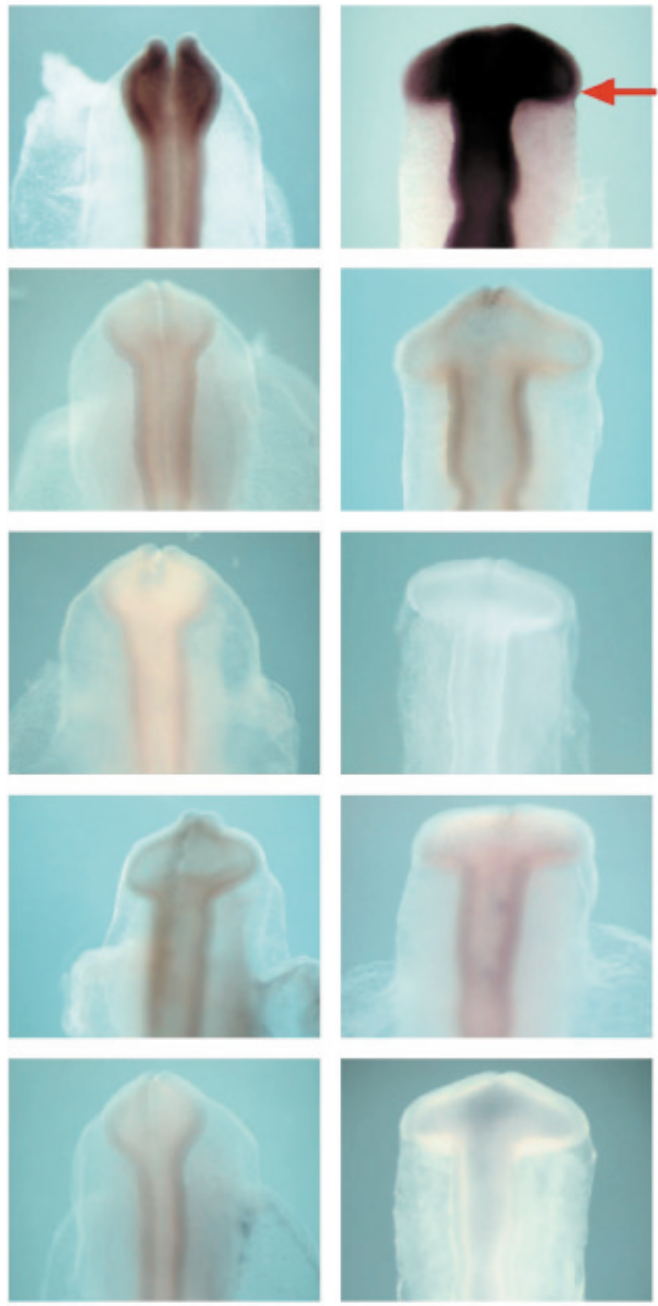

St. 9
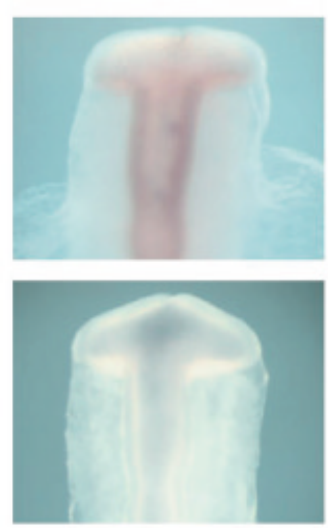

St. 10 invaginating placode express almost no Six3 (Oliver et al., 1995; Bovolenta et al., 1998; Reza et al., 2002). Taken together, these findings indicate that Pax6 induction of placode is accomplished by the combined effects of other, as yet unidentified regulatory genes.

\section{Sox2 in lens placode initiation}

Sox proteins are members of the Sry-related family of high mobility group domain (HMG) proteins. Upregulation of Sox2 expression is considered a marker of specified head ectoderm fully capable of inducing lens cells (Furuta and Hogan, 1998; AsheryPadan et al., 2000). Sox proteins alone are not sufficient to initiate transcription. Rather, they require partner molecules capable of binding to the same enhancer element (Kamachi etal., 1998; Yuan et al., 1995; Lefebvre et al., 1997). Sox2 expression starts in the ventral half of the head ectoderm prior to optic vesicle apposition,
Fig. 2. Sequential expression of several genes during lens development in chick. Chick embryos were staged according to the Hamburger and Hamilton (1951). Different staged embryos ranging from $\mathrm{HH} 9$ to $\mathrm{HH}$ 13 were collected and assigned to six groups, each group containing 6-10 embryos. These embryos were subjected to in situ hybridization using five different probes. Pax6 expression was detected in the ectodermal tissue at stage $\mathrm{HH} 9$ (top, arrow); in fact, the expression starts at a much earlier stage (HH stage 6, data not shown). Sox2 expression was found at stage 10 in the overlying ectoderm (2 ${ }^{\text {nd }}$ lane, arrow). L-Maf expression appears at stage 11 in the PLE (3 lane, arrow). C-Maf was visualized at stage 12 in the lens placode $\left(4^{\text {th }}\right.$ lane, arrow). Prox 1 was detected at stage $13\left(6^{\text {th }}\right.$ lane, arrow) and finally, $\delta$-crystallin expression was observed at late stage 13 in the lens placode (bottom lane, arrow). Arrows indicate the reactivity for the respective mRNAs.
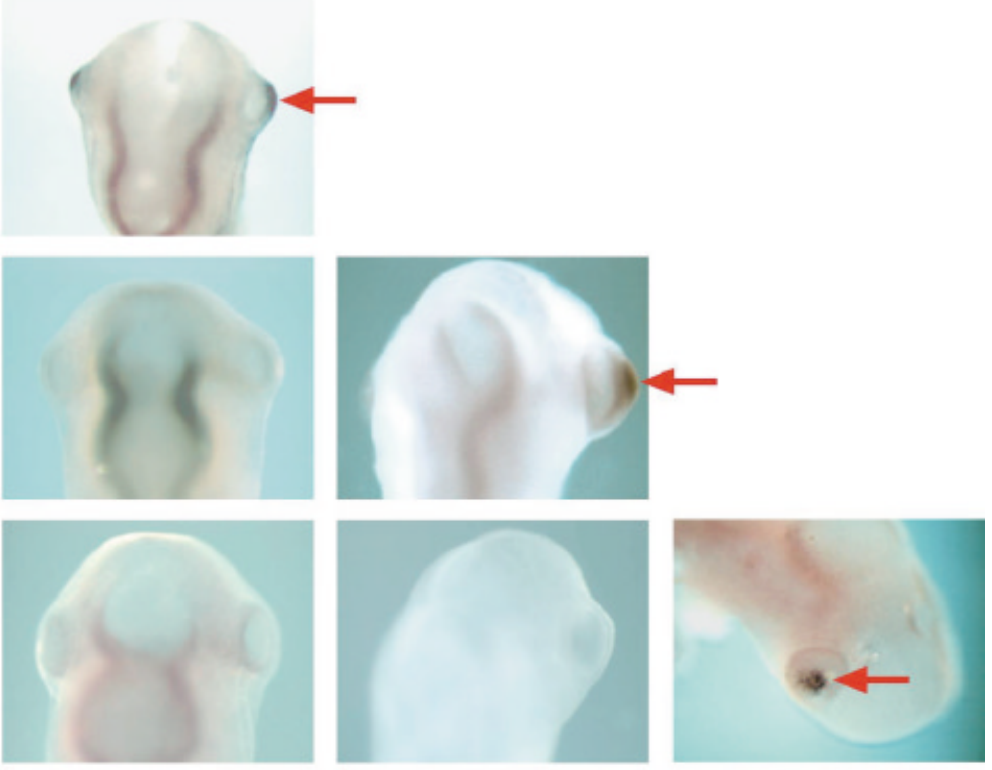

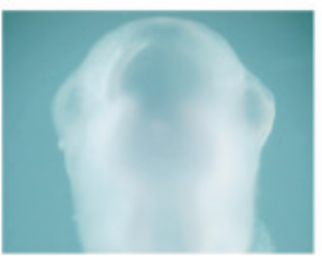

St. 11

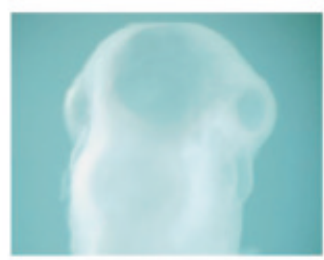

St. 12

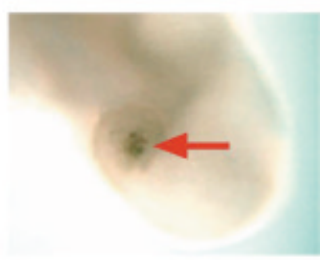

St. 13 becoming stronger at the time of contact in the lateral side facing the optic vesicle (Kondoh, 1999; Fig. 2). Sox3 expression is detected prior to placode formation in a smaller region facing the optic vesicle. During early development of the lens, the expression pattern of Sox2/3 generally coincides with that of Pax6, indicating that these three proteins provide the necessary conditions for head ectoderm (bias and specification) to initiate lens placode in response to inductive signals from the optic vesicle. Ablation of the optic vesicles resulted in inhibition of Sox2 activation and lens placode formation in chicks, emphasizing the essential roles for Sox2 in placode initiation (Kamachi et al., 1998).

\section{L-Maf in placode formation}

The mafgenes encode basic-leucine zipper (b-ZIP) transcription factors, which have motifs for DNA binding and dimerization 
and an acidic domain for transcriptional activation (Blank and Andrews, 1997; Reza and Yasuda, 2004). L-Maf is a lens-specific transcription factor first detected in the PLE immediately after contact between surface ectoderm and optic vesicle at stage 11 in chick. Since lens placode subsequently becomes evident with the thickening of the ectodermal cells, L-Maf is likely the cause of placode development (Ogino and Yasuda, 1998). Loss-of-function experiments using dominant-negative L-Maf resulted in a complete loss of placode structures, again suggesting that L-Maf is essential for placode formation (Reza et al., 2002). We recently found that overlying ectoderm expressing dominant-negative LMaf also expresses Sox2 (HMR, unpublished data), indicating that, even after full establishment of lens specification (Ashery-Padan et al., 2000), placode formation is hindered due to the absence of functional L-Maf in the PLE. The findings that inductive signals from optic vesicles are required for $L-M a f$ expression and that $L-M a f$ was able to rescue the effects of dominant-negative Pax6 in placodal cells (Reza et al., 2002), suggest that the extended role of Pax6 in the final step of lens specification is taken over by L-Maf. Thus, LMaf expression is a marker for the complete establishment of lens specification that precedes lens placode formation in the chick.

\section{Six 3 in placode formation}

Six3, a vertebrate homologue of the Drosophila sine oculis gene, is expressed in the mouse lens placode but is later restricted to the lens epithelium (Oliver et al., 1995). In chicks and medakas, Six3 expression in the PLE is detected earlier than in mice (Loosli etal., 1998; Bovolenta etal., 1998). The intense expression of Six3 in the PLE indicates its importance in placode formation. Interestingly, this expression disappears in the lens placode of medaka, whereas it persists in the lens placode of chick and is subsequently confined to the lens epithelium (Bovolenta et al., 1998; Reza et al., 2002), suggesting that Six3 may function to retain the undifferentiated state of lens epithelium in the chick. Although misexpression of Six3 in the medaka converts otic vesicles into lens cells, as evidenced by the expression of crystallin-expressing lens-like structures (Oliver et al., 1996), similar results have not been reported in any other species to date. In mice, Six3 has been found to repress $\gamma$-crystallin promoter activity when assayed in N/N1003A and CD5A cells (Lengler et al., 2001). A recent report demonstrates that gain of Six3 function in lens primordium by in ovo electroporation of chick embryos causes an arrest of lens placode invagination and suppresses lens fiber differentiation (Zhu et al., 2002). These observations suggest that Six3 is crucial for maintaining the state of undifferentiated lens epithelium required for proper morphogenesis.

\section{Other factors in lens placode development}

Several studies demonstrate that fork head family members, including Lens1 and Foxe3, take part in lens placode formation. Both of these proteins are expressed exclusively in the PLE and are positioned downstream of Pax6 in the gene cascade for lens development (Kenyon etal., 1999; Blixt etal., 2000; Brownell etal., 2000). Dysgenetic lens $(d y /)$ mice produced by a mutation in the foxe 3 gene exhibit accumulation of large amounts of Prox1, a protein that acts mainly in the terminal differentiation of fiber cells (Blixt et al., 2000; Brownell et al., 2000). Overexpression of Lens1 in Xenopus embryonic ectoderm induces lens ectoderm, which does not express crystallin. In mab21/1-mutant mice, defective lens placode formation is associated with suppressed expression of Foxe3 (Yamada et al., 2003). Taken together, these observations suggest that these genes play important roles in the induction and maintenance of lens placode.

Adhesion molecules have been found to play significant roles in cell growth and differentiation during organogenesis (Gumbiner, 1996; Yagi and Takeichi, 2000). N-Cadherin, which is first expressed at the time of placode formation, has been found to be involved in the separation of differentiated lens placode from ectodermal tissue, which continuously expresses E-cadherin (Hatta and Takeichi, 1986). Expression of Ap-2a occurs in head ectoderm prior to placode formation, but is later restricted to lens epithelium. In addition, $A p$-2a-knockout mice were found to exhibit defective lenses, which remain attached to the surface ectoderm (WestMays et al., 1999). AP-2a binding sites have been identified in the promoter elements of both $\mathrm{E}$ - and N-cadherin ( $\mathrm{Li}$ et al., 1997; Batsche et al., 1998), indicating that AP-2a spatio-temporally controls expression of $\mathrm{E}$ - and $\mathrm{N}$-cadherins to promote placode formation. In Xenopus, expression of a bicoid-related homeobox gene, Pitx 1, has been detected in the PLE and persists in the lens vesicle, suggesting its involvement in placode formation (Hollemann and Pieler, 1999).

\section{Role of optic vesicle in placode formation}

The optic vesicle plays an essential role in lens formation by providing inductive signals to the surface ectoderm in a step-wise fashion (Spemann, 1901; Lewis, 1904; Grainger, 1992; Grainger et al., 1988). Although a detailed discussion of the experimental evidence is beyond the scope of this review, the multi-step tissue interactions between the optic vesicle and head ectoderm have been shown to gradually trigger the PLE to form lens placode. The optic vesicle has been found to secrete various diffusible factors, including fibroblast growth factors (FGFs) and bone morphogenetic proteins (BMPs), which directly induce lens placode formation.

BMPs are secreted signaling molecules belonging to the TGF$\beta$ superfamily. Several lines of evidence have demonstrated that two BMPs, BMP4 and BMP7, are crucial for the early steps of the lens induction process. In mice, BMP4 is highly expressed in the dorsal region of the optic vesicle, but weakly expressed in the overlying surface ectoderm, whereas BMP7 is expressed in the prospective pigment epithelium (Dudley and Robertson, 1997; Furuta and Hogan, 1998; Wawersik et al., 1999). BMP7-mutant homozygous mice exhibit micropthalmic or anopthalmic phenotypes (Dudley et al., 1995), and, in severely affected BMP7-mutant mice, neither Pax6 expression nor lens placode formation is observed (Wawersik et al., 1999). In BMP4-null mutant embryos, lens formation is arrested, with a loss of Sox2 upregulation, but it can be rescued by applying exogenous BMP4 into the optic vesicle in explant culture (Furuta and Hogan, 1998). In contrast, applying BMP4 beads without optic vesicles does not induce lens formation. These observations indicate that BMP4 and one or more unknown signals from optic vesicles are required to form lens placode from the ectoderm.

In the chick, BMP4 expression is first detected in the PLE facing the optic vesicle prior to placode formation, and later in dorsal neural retina. In contrast, BMP7 expression is detected only in prospective pigment epithelium during optic vesicle invagination (Trousse et al., 2001). Since BMP4 is not present in optic vesicle 
tissue prior to placode formation in chick, it is evident that BMP4 signaling does not function in placode initiation in this species, emphasizing a functional demarcation between the mouse and chick. The BMPs, however, may regulate later steps of lens development in the chick.

Several FGFs have been shown to be involved in lens development. For example, in explant cultures, low levels of FGF2 were found to promote the proliferation of lens epithelial cells (McAvoy and Chamberlain, 1989; Ochi et al., 2003). In the chick, FGF8 expression is first apparent in the anterior neural plate at stage 9 and thereafter, in the distal optic vesicle around the time of its contact with the head ectoderm. This pattern of FGF8 expression, which is observed earlier than L-Maf expression in the PLE, suggests that FGF8 is the most potential candidate among the lens inductive signals stimulating L-Maf expression as well as placode induction. This is further supported by the fact that when FGF8, in the form of acrylic beads, was applied after contact of the optic vesicle with surface ectoderm, formation of ectopic lens placode, expressing high levels of L-Maf, was observed (Vogel-Hopker et al., 2000).

FGF receptors are similarly expressed in the lens lineage (de longh et al., 1996, 1997). Tfr7 transgenic mice expressing dominant-negative FGF receptors coupled to the lens enhancer/promoter PO, which is driven only by ectodermal Pax6, show poorly developed lens placode (Faber et al., 2001). Lens vesicle is also found attached to surface ectoderm in these mice. The expression of Pax6 and Sox 2 in lens placode is significantly decreased when FGF receptor is inactivated in presumptive lens ectoderm, suggesting that expression of Pax6 and Sox2 lies downstream of FGF signaling in the lens induction pathway (Faber et al., 2001). Although FGF signaling participates in proper development of lens placode, elucidation of the exact roles of all members of the FGF family is necessary to determine whether FGF molecules act as early lens inductive signals.

In mouse embryos, deletion of the $L h \times 2$ gene, which encodes one of the transcription factors expressed in optic vesicle, blocks placode formation, and Pax6 is not expressed in overlying ectoderm (Porter et al., 1997). These findings suggest that Lhx2 may play a role in lens specification as well as in placode formation by maintaining Pax6 expression in overlying surface ectoderm.

\section{Lens differentiation and crystallin expression}

Lens differentiation first manifests as the appearance of placodal cells derived from ectodermal epithelium. At the beginning of lens differentiation, several transcription factors are expressed, each with distinct functions. During the process of lens differentiation, these factors contribute to the smooth formation of lens vesicles. The lens placode invaginates, gradually assuming a spherical shape and forming the lens vesicle, which then becomes separated from the ectoderm (Fig. 1). The cells on the inner side of the lens vesicle differentiate into primary fiber cells, while cells on the outer side form the lens epithelium. The equatorial region acts as a transition state, where cuboidal cells undergo continuous proliferation and differentiation, subsequently contributing to the formation of secondary fiber cells.

Lens differentiation is associated with the sequential activation of the crystallins (Wistow and Piatigorsky, 1988; Cvekl and Piatigorsky, 1996; Ogino and Yasuda, 2000). These water soluble lens proteins constitute a group of structural molecules that are present at high concentration in lens, making lens transparent and refractive to light (Piatigorsky, 1992; Cvekl and Piatigorsky, 1996; Bhat, 2003). About $90 \%$ of the soluble proteins in the lens are crystallins (de Jong, 1981). Although crystallins are also expressed in other tissues, their refractive properties are utilized only in lens (Cvekl and Piatigorsky, 1996). The $\alpha$ - and $\beta$-crystallins are well conserved in all major vertebrates (Ogino and Yasuda, 2000). Although $\gamma$-crystallins are present in mammals, these proteins, except for $\gamma S$, are absent from avian species (Van Rens et al., $1991)$. The primary crystallin in the chick is $\delta$-crystallin, a taxonspecific gene similar to argininosuccinate that is expressed only in avian and reptile species. The $\delta$-crystallin protein first becomes apparent in the lens placode stage. In subsequent developmental stages, $\alpha$ - and $\beta$-crystallins, along with $\delta$-crystallin, are expressed in chicks, each with a distinct spatio-temporal specificity.

\section{Mechanisms of $\delta$-crystallin regulation}

The process of lens differentiation from the head ectoderm is accomplished by a number of developmentally regulated gene functions. This has led us to hypothesize that expression of a particular gene is likely to be regulated by several pathways, dependent upon the availability of the regulatory proteins at different stages in development. Changes in gene regulation are probably associated with new functions of an existing protein or expression of a new protein phenotype (Piatigorsky, 2003).

The first crystallin to be expressed in chick lens is $\delta$-crystallin, which is first detected in the lens placode of $\mathrm{HH}$ stage 13 embryos (Fig. 2). Expression of this protein continues during lens development, with the level of expression becoming higher in lens fiber cells than in lens epithelium. Evidence now suggests that $\delta$ crystallin expression is regulated by different regulatory factors sequentially determined by the developmental stages. The lensspecific enhancer of the $\delta$-crystallin gene, which is located in its third intron, acts as the major binding site for proteins regulating expression of this gene (Hayashi et al., 1987). Regulation of $\delta$ crystallin gene expression has been studied primarily using cultured cells derived from chicken lens epithelial cells, a transgenic mouse model in which $\delta$-crystallin is never expressed, and in ovo microelectroporation of chick embryos.

At a very early stage of development, when lens placode formation has begun, expression of Pax 6 and Sox 2 are detected in placodal cells (Kamachi et al., 1998). In vitro experiments demonstrate that $\mathrm{Pax} 6$ binds to the promoter regions of the mouse $\alpha A$-and $\alpha B$-, chick $\delta$-, and guinea-pig $\zeta$-crystallin genes, activating their expression (Cvekl et al., 1994; Cvekl et al., 1995; Richardson etal., 1995), and supporting the hypothesis that Pax6 regulates these genes. We and others have shown that targeted inactivation of Pax6 in lens primordium inhibits expression of the crystallins as well as lens formation, which is attributed to the downregulation of several other transcription factors (AsheryPadan et al., 2000; Reza et al., 2002). In contrast, several Sox proteins, including Sox1, Sox2 and Sox3, have been shown to activate the enhancer/promoter of the $\delta$-and $\gamma$-crystallingenes in lens cells (Kamachi et al., 1995). In addition, misexpression of Sox3 in medaka induces ectopic lens formation (Koster et al., 2000). Both Sox2 and Sox3 are normally expressed in the wider domain of PLE. Therefore, it is conceivable that the earliest 
mechanism underlying $\delta$-crystallin expression is governed by Pax6 and Sox2 (Fig. 4A).

The minimal lens-specific enhancer DC5, which contains binding sites for Sox2 and Pax6 (Fig. 3B), has been found to drive transcription of the $\delta$-crystallin gene. Sox 2 and Pax6 thus form a complex that binds to the DC5 element of enhancer DNA, leading to the synergistic transcription of the $\delta$-crystallin gene (Kamachi et al., 2001). This is supported by the finding that co-expression of Pax6 and Sox2 leads to formation of ectopic lens placode expressing $\delta$-crystallin (Kamachi et al., 2001; Reza et al., 2002). Since this ectopic lens placode can only be formed close to endogenous lens, it is possible that additional inductive signals from the optic vesicle are required to trigger endogenous $\delta$-crystallin expression. In addition, since Pax 6 and Sox 2 are both expressed in epithelial cells during the ensuing stages of development, this mechanism may be operative only in early lens placode and later lens epithelium, that continues to express a low level of $\delta$-crystallin. This is supported by findings from a recent transgenic mouse study, showing that mutation of two Maf binding sites present on either side of the BN region, a 120bp long fragment capable of activating lens-specific enhancer activity, significantly reduced reporter activity in fiber cells but not in epithelium (Muta et al., 2002). However, this mechanism of $\delta$-crystallin regulation, while developmentally important, may be short-lived.

Ectopic lens placode induced by co-expression of Pax6 and Sox2 also exhibited marked expression of L-Maf. Since endogenous L-Maf is expressed in the PLE before $\delta$-crystallin expression and has been shown to activate $\delta$-crytallin (Ogino and Yasuda, 1998; Reza et al., 2002; Reza and Yasuda 2004), it is likely that the earliest expression of $\delta$-crystallin expression is due, at least in part, to the synergistic activity of Pax6 and Sox 2 and subsequently to these two factors plus L-Maf. This hypothesis is supported by our observation of putative binding sites for both Pax6 and Sox2 in the 5'-flanking region of the L-mafgene (Fig. $3 A)$. In addition, data derived from our protein-DNA gel-shift experiments showed that L-Maf can bind to the DC5 element, indicating that the latter possesses binding sites for L-Maf (TY, HMR and KY, unpublished data) as well as for Pax6 and Sox2 (Muta et al., 2003). Interestingly, the L-Maf binding site of DC5 overlaps the Pax6 site (Fig. 3B), suggesting that, in the initial lens placode, Pax 6 and Sox 2 activate $\delta$-crystallin only to a minor extent prior to L-Maf expression (Fig. 4A). Once L-Maf expression is induced in the PLE by Pax6 and Sox2, L-Maf can substitute for Pax6, binding to its target sequence on DC5 and functioning in concert with Sox2. Alternatively, Pax6, Sox2 and L-Maf may form a ternary complex, which binds to the enhancer element responsible for $\delta$-crystallin expression.

As lens development proceeds, the lens vesicle forms and fiber differentiation begins in the posterior cells of the lens vesicle. Pax6 continues to be expressed in the surface ectoderm overlying the optic vesicles, later becoming restricted to the proliferating epithelial cells of the developing lens and turning down from the differentiating fiber cells (Grindley et al., 1995). Pax6 has been shown to bind to the promoter sequence of mouse lens fiber-specific $\beta B 1$ crystallin, where it acts as a repressor (Duncan et al., 1998), This is consistent with the fact that Pax6 expression remains very low in the fiber cells and indirectly favors the high expression of fiberspecific gene $\beta B 1$-crystallin. Nevertheless, this lower expression level of Pax6 suggests that a different regulatory factor capable of transcribing $\delta$-crystallin and/or other fiber-specific genes plays major role in fiber cells.

L-Maf is highly expressed in lens placode and subsequently in fiber cells and in cells positioned in the equatorial region. Several lines of evidence indicate that L-Maf is the principal regulator of the $\delta$-crystallin gene. For example, misexpression of L-Maf is able to convert non-lens cells to lens cells, characterized by the expression of $\delta$-crystallin, in cell culture systems and chick embryos (Ogino and Yasuda, 1998). In addition, dominant-negative Pax6 inhibits $\delta$-crystallin expression as well as placode formation, and this phenotype is also observed with dominant-negative L-Maf. Interestingly, the dominant-negative Pax6 effect is rescued by wild-type L-Maf in developing lens cells, providing further evidence that Pax6 function is mediated by L-Maf and that L-Maf is the right candidate to elicit the high lens expression of $\delta$-crystallin (Reza et al., 2002). Thus, it is reasonable to postulate that L-Maf is the major regulator of $\delta$-crystallin expression after placode formation (Fig. $4 A)$.

In regulating $\delta$-crystallin, however, L-Maf usually functions in a Sox2-dependent manner (Reza et al., 2002; Shimada et al., 2003). Sox2 has been shown to act in cooperation with L-Maf to enhance $\delta$-crystallin gene transcription through the same third intron enhancer element. A longer region $(\mathrm{BHd})$, which contains DC5 in addition to several putative Sox2 and Maf binding sites (Fig. 3B), is required for this cooperative effect (Shimada et al., 2003). Since the Sox proteins bind DNA with lower affinity, they can only function in gene regulation by partnering with other proteins. Thus, in lens

A L-Maf (5' upstream region)

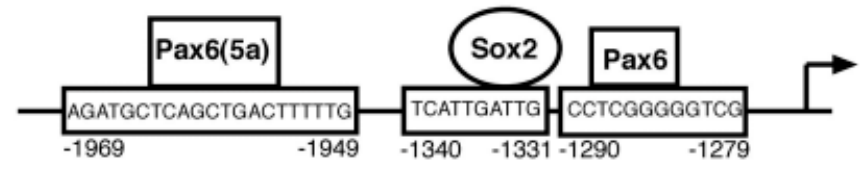

B

d-crystallin enhancer (3rd intron)

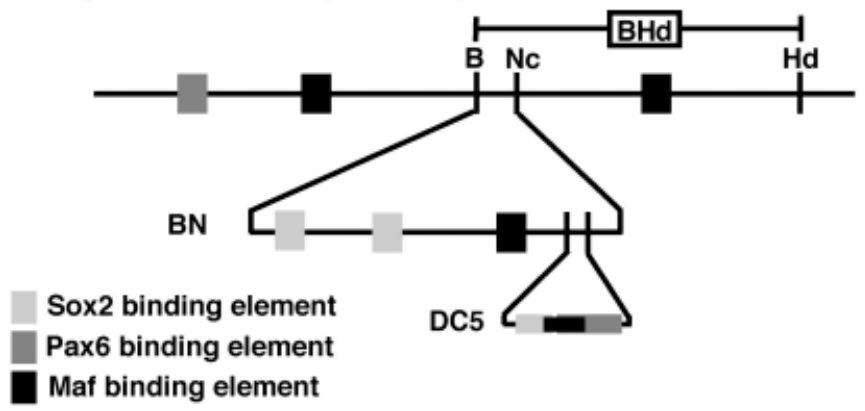

Fig. 3. Schematic representation of putative binding sites in regulatory regions of the respective genes. (A) Putative binding sites for Pax6/ Pax6(5a) and Sox2 in the 5'- upstream region of the L-maf gene. The nucleotides shown in the boxes are very similar to the consensus binding sequences for Pax6/Pax6(5a) and Sox2 (Epstein et al., 1994ab; Muta et al., 2002). (B) Different regions $B H d, B N$ and DC5 including binding sites for Pax6, Sox2 and Maf are shown in the enhancer element of the $\delta$-crystallin gene. 
fiber cells, Sox2 must partner with L-Maf, which binds DNA with high affinity, to regulate $\delta$-crystallin.

In addition, proteins encoded by the $c$-mafand Prox 1 genes can independently upregulate crystallin expression in fiber cells. c-Maf, another member of the large family of b-ZIP Maf proteins, is structurally similar to L-Maf. In placodal cells of the chick embryo, c-Maf expression starts a few hours later than L-Maf expression (Reza and Yasuda, 2004). In our gain-of-function experiments using both cultured cells and embryos, we found that c-Maf was able to activate $\delta$-crystallin expression, but not as strongly as L-Maf (Yoshida and Yasuda, 2002; HMR and KY unpublished). The necessity for c-Maf or other factors having functions similar to LMaf at the same point in development may thus be questioned. This type of redundancy may be necessary, however, to ensure that proper development takes place fully. Additional factors may also be needed to meet increased demand after lens vesicle formation, when there is increased need for structural proteins that provide proper shape and size of the lens. Later in development, however, c-Maf expression becomes restricted to the lens epithelium (Reza and Yasuda, 2004). These observations indicate that c-Maf and LMaf regulate $\delta$-crystallin expression in parallel for a short period of time, in order to synthesize the optimum level of protein necessary for normal growth of the lens (Fig. 4A).

The homeobox gene Prox 1 is a vertebrate homologue of the Drosophila prosperogene. In Drosophila, prosperois expressed in lens secreting cone cells and in the central nervous system, where it is asymmetrically divided into the mother ganglion cells necessary for subsequent gene expression in these cells (Hirata et al., 1995). Prox1 expression in the chick lens placode has been shown to precede $\delta$-crystallin expression (Tomarev et al., 1996; Fig. 2).
Consistent with this expression pattern, we have found that misexpression of Prox 1 in chick embryos has only a slight effect on $\delta$-crystallin expression, indicating that Prox 1 has little effect on $\delta$ crystallin regulation (Reza et al., 2002). The dominant-negative forms of both Pax6 and L-Maf suppress Prox1, suggesting that this protein acts downstream of Pax6 and L-Maf in the gene cascade regulating lens development (Fig. 4A).

Overexpression of the transcription factor Six 3 has been shown to inhibit the expression of $\delta$-crystallin in developing lens cells; this effect is thought to be mediated by an ATTA-motif present in the $\delta$ crystallin enhancer (Zhu et al., 2002). This finding suggests that, in mature lens epithelial cells, Six 3 suppresses $\delta$-crystallin expression and possibly maintains the proliferative property of lens epithelium (Fig. 4A).

\section{Mechanisms of regulation of other crystallins}

The $\alpha$ - and $\beta$-crystallins are two other members of the cyrstallin family abundantly expressed in the chick lens. Although all crystallins are functionally similar, especially in terms of their refractive properties in lens, their patterns of spatio-temporal expression during lens development suggest the involvement of differing upstream interacting factors at different times. Indeed, several regulatory proteins are believed to activate the different lens crystallins. Accumulating evidence suggests that crystallins other than $\delta$-crystallin are regulated by a mechanism similar, but not identical to that regulating $\delta$-crystallin during the course of development (Fig. 4B).

Transfection experiments and EMSA analysis have shown that the regulatory region of $\alpha A$-crystallin gene has at least three
Fig. 4. Two proposed models of crystallin regulation during chick lens development. (A) The possible mechanism underlying $\delta$-crystallin regulation. Pax 6 and Sox2 expressed in the presumptive lens ectoderm induce $\delta$-crystallin in the initial lens placode in response with some optic vesicle inductive signals, maybe FGF8 or others (red). L-Maf, which is simultaneously activated by these upstream factors also induces $\delta$-crystallin in the initial lens placode. Later, L-Maf regulates $\delta$-crystallin expression in the invaginating lens placode and lens fiber. Sox 2 exerts its cooperative action together with L-Maf. c-Maf and Prox 1 are also directly involved in this process. Six3, however, suppresses $\delta$ crystallin expression in the epithelial cells and may support the expression of epithelium spe-
A

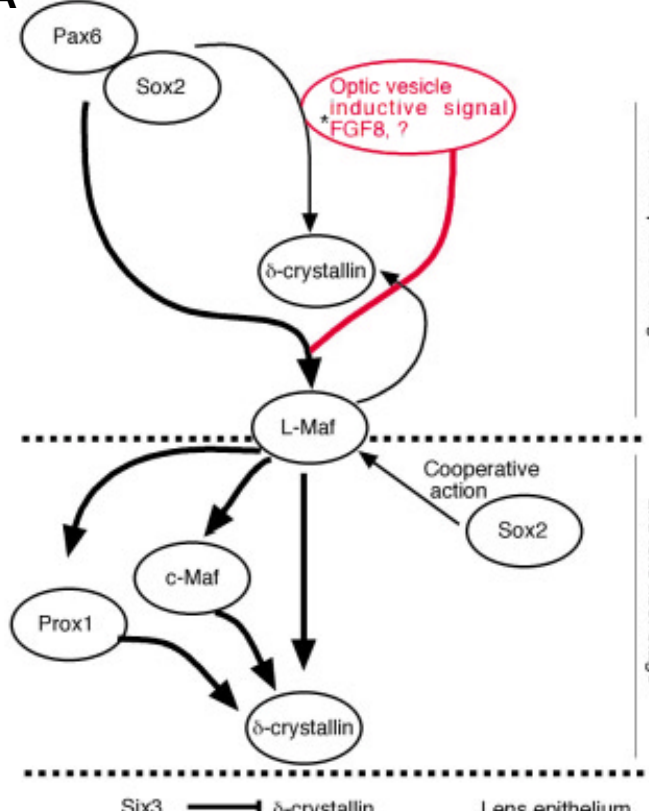

B

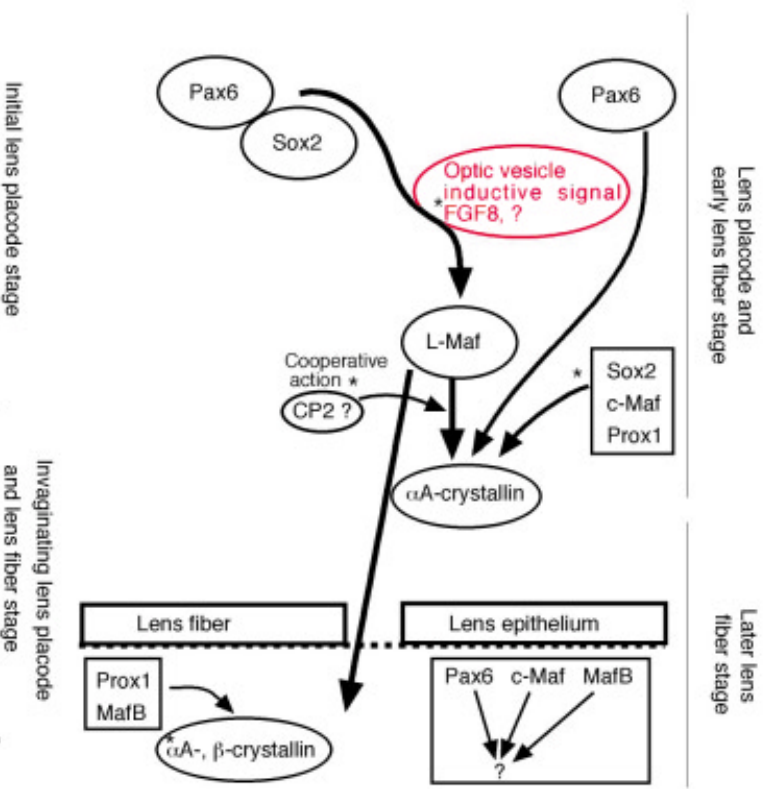

cific genes. (B) The model showing the regulation pathways of other crystallins expressed in lens. Pax 6 and Sox 2 together with the inductive signals, which may be FGF8 or others (red), from the optic vesicle induce lens specific L-Maf which initiates $\alpha A$-crystallin at lens vesicle stage and in early lens fiber. The CP2 probably acts in synergy with L-Maf to trigger $\alpha A$-crystallin expression. Sox2, c-Maf and Prox 1 are also possibly involved in $\alpha A$-crystallin expression. $L$-Maf continues to stimulate $\alpha A$-crystallin and activates $\beta$-crystallin in fiber cells at a much later stage. Prox 1 and MafB are likely to enhance $\beta$-crystallin in the fiber cells while the functions of Pax6, c-Maf and MafB in the lens epithelium need to be addressed. Asterisk (*) indicates the speculative events. 
binding sites to which Pax6 can bind directly (Cvekl et al., 1994). EMSA analysis has further revealed that USF and CREB/CREM proteins bind to the respective sites present in the regulatory region of this gene. Thus, it has been demonstrated that $\mathrm{Pax} 6$ regulates $\alpha A$-crystallin gene in concert with USF and CREB/CREM in lens cells (Cvekl et al., 1994). We assume that this regulation persists at the earlier phase of $\alpha \mathrm{A}$-crystallin expression when L-Maf proteins continue to accumulate to a significant level. Pax6 and Sox2 in the lens placode may also form an active complex to initiate $\alpha A$ crystallin, by a mechanism similar to the induction of $\delta$-crystallin expression. However, expression of $\alpha \mathrm{A}$-crystallin, which is detected at a high level in developing lens, is thought to be mainly regulated by L-Maf directly. L-Maf is highly expressed in these cells before the onset of $\alpha \mathrm{A}$-crystallin expression, and L-Maf has been shown to enhance reporter activity through the $\alpha \mathrm{CE} 2$ sequence, one of the two enhancer elements of the $\alpha A$-crystallin gene (Matsuo and Yasuda, 1992), as well as to bind specifically to this $\alpha$ CE2 sequence. Misexpression of L-Maf in cultured retina cells has been shown to lead to abundant expression of $\alpha$ A-crystallin (Ogino and Yasuda, 1998). In cultured cells, L-Maf has been found to be unable to enhance the activity of a reporter containing six copies of the $\alpha \mathrm{CE} 2$ core sequence that had been determined to be the L-Maf binding site, indicating that L-Maf induction of $\alpha A$ crystallin expression also requires the binding of another factor to a neighboring site in the $\alpha$ A-crystallin promoter/enhancer (Yoshida and Yasuda, 2002). Since we previously showed that two enhancer elements, $\alpha \mathrm{CE} 1$ and $\alpha \mathrm{CE} 2$, direct the expression of the $\alpha A$ crystallingene (Matsuo and Yasuda, 1992), and that a ubiquitously expressed transcription factor, CP2, can bind to the $\alpha \mathrm{CE} 1$ element (Murata et al., 1998), it is likely that L-Maf and CP2 function synergistically to activate the $\alpha A$-crystallingene and contribute to the high lens expression of this gene (Fig. 4B). In this case, it is possible that CP2 and L-Maf bind to the respective sites and cooperatively favor the recruitment of other necessary factors to the promoter of $\alpha A$-crystallingene.

We also found that C-Maf is more active than L-Maf in activating luciferase activity driven by the $\alpha \mathrm{CE} 2$ element of $\alpha \mathrm{A}$-crystallin enhancer (Yoshida and Yasuda, 2002), suggesting that, unlike LMaf, c-Maf can independently activate $\alpha$ A-crystallin in lens cells. This is supported by our finding that misexpression of L-Maf induces $\alpha A$-crystallin expression in a wider domain, one in which Sox2 is absent but CP2 is present (N.S. and KY, unpublished). Prox1, which is abundantly present in the developing lens cells beginning at the placode-invaginating stage, may also regulate $\alpha A$-crystallin expression in the chick.

In both the chick and mouse, Sox1 was found to be first expressed at the lens vesicle stage, and its expression during development was observed to persist, even after the disappearance of Sox2 (Nishiguchi et al., 1998; Kondoh, 1999). Sox1knockout mice exhibit phenotypes resembling microphthalmia and cataracts, with a loss of $\gamma$-crystallin expression. In these mutant mice, elongation of posterior fiber cells is arrested and the lens cavity remains empty, resulting in a hollow lens (Nishiguchi et al., 1998), suggesting that Sox 1 induces expression of $\gamma$-crystallin. In the chick, Sox 1 may regulate $\alpha \mathrm{A}$-crystallin expression by a similar mechanism.

The $\beta$-crystallins are expressed much later during lens development. These proteins are detected in differentiated fiber cells of developing lens, at stages when Sox2 expression declines but L-
Maf, c-Maf and MafB are present, along with Sox1. Misexpression of L-Maf activates $\beta B 1$-crystallin expression (Ogino and Yasuda, $1998)$, indicating that $L-M a f$ may regulate $\beta B 1$-crystallin expression in fiber cells (Fig. 4B). By contrast, it has been found that Pax6 binds to the promoter sequence of the chick $\beta B 1$-crystallin gene and represses its activity (Duncan etal., 1998), a finding consistent with the later expression pattern of Pax6, which is confined to the lens epithelium where $\beta B 1$-crystallin is not expressed. A very recent work demonstrates that $c-M a f$ and MafB proteins regulate $\beta B 1$-crystallin in lens fiber cells and Pax 6 represses its expression in lens epithelium (Cui et al., 2004).

Prox1 has been shown to be essential for the terminal differentiation of lens fiber cells in mice (Wigle et al., 1999). In Prox1homozygous mutant mice, lens cells fail to polarize and elongate properly, resulting in a hollow lens characterized by the abrogation of the later expressed fiber-specific genes, $\gamma B$-and $\gamma D$-crystallins. Recent findings show that Prox1 expression is redistributed during fiber cell differentiation, remaining for long periods in the nuclei of the cells that undergo denucleation (Duncan et al., 2002). These findings suggest a possible role for Prox 1 in the regulation of later expressed $\beta$-crystallin in chick lens fiber cells (Fig. 4B). Prox1 binding to the promoter of chick bB1-crystallin and thereby regulating its expression has recently been obtained (Cui et al., 2004). Using cell lines, Prox 1 was shown to activate $\gamma$-crystallin expression through the responsive element located between nt-151 and nt-174 of the gene promoter (Lengler et al., 2001), suggesting that Prox1 may exert some regulatory effects on later expressed crystallins, including $\beta$-crystallin, in the chick.

\section{Neural retina: a source of signaling factors essential for continued differentiation of lens fiber}

As described above, the optic vesicle has been shown to be a source of the initial signals of lens induction. At later stages, however, when the optic cup has been formed and posterior cells in the lens vesicle undergo extensive differentiation, reciprocal signaling becomes important for correct formation of both the lens and retina (Coulombre and Coulombre, 1964). The differential expression pattern of BMP4 at different stages suggests it has multiple roles during eye development (Trousse et al., 2001; Faber et al., 2002). At stage 24, BMP4 expression is extremely localized to the dorsal region of the neural retina, covering the marginal tip. A recent study shows that optic cup formation is arrested, however, lens-fiber differentiation is partially affected when exposed to high level of exogenous BMP4 (Hyer et al., 2003), suggesting that optimum level of BMP4 is essential for normal development of optic cup and neural retina, which in turn maintains necessary signaling between lens and retina required for proper lens morphogenesis.

Like BMP4, other members of the TGF $\beta$ superfamily may also participate in lens fiber differentiation. Overexpression of TGF $\beta 1$ in transgenic mice lens was shown to result in opacity similar to cataract (Srinivasan et al., 1998), and TGF $\beta$ was found to produce cataractous changes in rat lens cell cultures (Gordon-Thomson et al., 1998). The members of the TGF $\beta$ family mediate their effects through TGF $\beta$ receptors Types I and II, both of which are abundantly expressed in developing lens fiber cells, primarily in the transition zone where the differentiation and elongation of fiber cells occur. Blocking of TGF $\beta$ receptor activity in the lens subsequently inhibits the TGF $\beta$ signaling pathway, which results in 
nuclear cataracts associated with altered expression of fiberspecific genes in transgenic mice (Gordon-Thomson et al., 1998). All these observations suggest the importance of TGF $\beta$ signaling in lens fiber differentiation.

FGF is another signaling molecule that regulates lens fiber differentiation (Schulz et al., 1993; Lang, 1999; Vogel-Hopker et al., 2000; Le and Musil, 2001). Targeted expression of FGF1/4/7/ $8 / 9$ under the control of lens specific $\alpha A$-crystallin exhibits ectopic fiber differentiation in mouse lens (Robinson et al., 1995; Lovicu and Overbeek, 1998). Exogenous application of FGF8 protein activates L-Maf expression in chick (Vogel-Hopker et al., 2000). Analogously, several members of the FGF receptor family are expressed in the lens lineage (de longh et al., 1996, 1997), and delayed fiber differentiation has been documented in Tfr7-transgenic mice expressing dominant-negative FGF receptors (Chow and Lang, 2001). Taken together, these results clearly show the importance of FGF8 at different stages of lens fiber differentiation, but the distinct functions of FGF signaling in proliferation and differentiation during lens development remain to be determined.

\section{Conclusions}

The detailed study of lens development in various species has substantially advanced our understanding of this process. Experimental data suggest that an ordered genetic network controls the molecular events that are indispensable for making a healthy lens. Homologous genes have been shown to exert very similar but not identical effects in all species, indicating that the rudimentary lens induction program follows a common genetic pathway. We have identified several genes essential for lens development and we have begun to elucidate the role of each in the development pathway. Many as yet unidentified genes, however, remain to be determined, as demonstrated by cDNA microarray analysis of transcripts derived from the lenses of transgenic mice overexpressing Pax6 in lens fiber (Chauhan et al., 2002).

The involvement of each member of a gene family associated with lens development also remains to be determined. Each of these genes may be regulated at different stages of development, or each may regulate the expression of different downstream genes. For example, both L-Maf and c-Maf are expressed in the lens placode at early stages of chick lens development, but at later stages, L-Maf expression is confined to fiber cells while c-Maf expression is restricted to the epithelium. During mitosis, the intrinsic properties of some cells can segregate protein determinants to one of the two daughter cells, thus determining the fate of the cell. Therefore, it will be of great interest to determine the factors precisely regulating asymmetric cell division in the germinative zone, such that L-Maf and c-Maf are differentially localized.

Many such questions remain. In addition to transcription factors, signaling proteins have emerged as potent determinants of lens formation. The molecular interactions between these secreted proteins and transcription factors are largely unknown. Continued research will determine each step in each regulatory pathway, thus improving our understanding of the molecular mechanisms of vertebrate lens morphogenesis.

\section{Acknowledgements \\ We thank Drs. Y. Kageyama, K. Kataoka, T. Yoshida and N. Shimada for their helpful discussions. This work was supported in part by Grants-}

in-Aid for The 21st Century COE Program from the Ministry of Education, Science, Sports and Culture of Japan. H.M. Reza is a recipient of COE fellowship.

\section{References}

ACAMPORA, D., MAZAN, S., LALLEMAND, Y., AVANTAGGIATO, V., MAURY, M., SIMEONE, A. and BRULET, P. (1995). Forebrain and midbrain regions are deleted in Otx2-/- mutants due to a defective anterior neuroectoderm specification during gastrulation. Development 121: 3279-3290.

ANG, S. L., JIN, O., RHINN, M., DAIGLE, N., STEVENSON, L. and ROSSANT, J (1996). A targeted mouse Otx2 mutation leads to severe defects in gastrulation and formation of axial mesoderm and to deletion of rostral brain. Development 122: 243-522.

ASHERY-PADAN, R. and GRUSS, P. (2001). Pax6 lights-up the way for eye development. Curr. Opin. Cell Biol. 13: 706-714

ASHERY-PADAN, R., MARQUARDT, T., ZHOU, X. and GRUSS, P. (2000). Pax6 activity in the lens primordium is required for lens formation and for correct placement of a single retina in the eye. Genes Dev. 14: 2701-2711.

BATSCHE, E., MUCHARDT, C., BEHRENS, J., HURST, H. C. and CREMISI, C. (1998). RB and C-Myc activate expression of the E-cadherin gene in epithelial cells through interaction with transcription factor AP-2. Mol. Cell. Biol. 18: 3647 3658.

BHAT, S. P. (2003). Crystallins, genes and cataract. Prog. Drug Res. 60: 205-262.

BLANK, V. and ANDREWS, N. C. (1997). The Maf transcription factors: regulators of differentiation. Trends Biochem. Sci. 22: 437-441.

BLIXT, A., MAHLAPUU, M., AITOLA, M., PELTO-HUIKKO, M., ENERBACK, S. and CARLSSON, P. (2000). A forkhead gene, FoxE3, is essential for lens epithelial proliferation and closure of the lens vesicle. Genes Dev. 14: 245-254.

BOVOLENTA, P., MALLAMACI, A., PUELLES, L. and BONCINELLI, E. (1998). Expression pattern of cSix3, a member of the Six/sine oculis family of transcription factors. Mech. Dev. 70: 201-203.

BROWNELL, I., DIRKSEN, M. and JAMRICH, M. (2000). Forkhead Foxe3 maps to the dysgenetic lens locus and is critical in lens development and differentiation. Genesis 27: 81-93.

CHALEPAKIS, G., FRITSCH, R., FICKENSCHER, H., DEUTSCH, U., GOULDING M. and GRUSS, P. (1991). The molecular basis of the undulated/Pax-1 mutation. Cel/66: 873-884.

CHANG, C. P., JACOBS, Y., NAKAMURA, T., JENKINS, N. A., COPELAND, N. G. and CLEARY, M. L. (1997). Meis proteins are major in vivo DNA binding partners for wild-type but not chimeric Pbx proteins. Mol. Cell. Biol. 17: 56795687.

CHAUHAN, B. K., REED, N. A., YANG, Y., CERMAK, L., RENEKER, L., DUNCAN M. K. and CVEKL, A. (2002). A comparative cDNA microarray analysis reveals a spectrum of genes regulated by Pax6 in mouse lens. Genes Cel/s 7: 12671283.

CHOW, R. L., ALTMANN, C. R., LANG, R. A., and HEMMATI-BRIVANLOU A (1999). Pax6 induces ectopic eyes in a vertebrate. Development 126: 42134222.

CHOW, R. L. and LANG, R. A. (2001). Early eye development in vertebrates. Annu. Rev. Cell. Dev. Biol. 17: 255-296.

COULOMBRE, A.J. and COULOMBRE, J.L. (1964). Lens development, I. Role of the lens in eye growth. J. Exp. Zool. 156; 39-47.

CUI, W., TOMAREV, S. I., PIATIGORSKY, J., CHEPELINSKY, A.B. and DUNCAN, M. K. (2004). Mafs, Prox1 and Pax6 can regulate chicken beta B1-cystallin gene expression. J. Biol. Chem. 279: 11088-11095.

CVEKL, A. and PIATIGORSKY, J. (1996). Lens development and crystallin gene expression: many roles for Pax-6. Bioessays 18: 621-630.

CVEKL, A., SAX, C. M., BRESNICK, E. H. and PIATIGORSKY, J. (1994). A complex array of positive and negative elements regulates the chicken alpha $A$-crystallin gene: involvement of Pax-6, USF, CREB and/or CREM, and AP-1 proteins. Mol. Cell. Biol. 14: 7363-7376.

CVEKL, A., SAX, C. M., LI, X., MCDERMOTT, J. B. and PIATIGORSKY, J. (1995). Pax-6 and lens-specific transcription of the chicken delta 1-crystallin gene. Proc. Natl. Acad. Sci. USA 92: 4681-4685. 
DE IONGH, R. U., LOVICU, F. J., CHAMBERLAIN, C. G. and MCAVOY, J. W. (1997). Differential expression of fibroblast growth factor receptors during rat lens morphogenesis and growth. Invest. Ophthalmol. Vis. Sci. 38: 1688-1699.

DE IONGH, R. U., LOVICU, F. J., HANNEKEN, A., BAIRD, A. and MCAVOY, J. W. (1996). FGF receptor-1 (flg) expression is correlated with fibre differentiation during rat lens morphogenesis and growth. Dev. Dyn. 206: 412-426.

DE JONG, W. W. (1981). Evolution of lens and crystallins. In Molecular and cellular biology of the eye lens (ed. H. Blomendal), pp. 221-278. Wiley, New York, NY.

DUDLEY, A. T., LYONS, K. M. AND ROBERTSON, E. J. (1995). A requirement for bone morphogenetic protein-7 during development of the mammalian kidney and eye. Genes Dev. 9: 2795-2807.

DUDLEY, A. T. and ROBERTSON, E. J. (1997). Overlapping expression domains of bone morphogenetic protein family members potentially account for limited tissue defects in BMP7 deficient embryos. Dev. Dyn. 208: 349-62.

DUNCAN, M. K., CUI, W., OH, D. J. and TOMAREV, S. I. (2002). Prox1 is differentially localized during lens development. Mech. Dev. 112: 195-198.

DUNCAN, M. K., HAYNES, J. I., 2ND, CVEKL, A. and PIATIGORSKY, J. (1998). Dual roles for Pax-6: a transcriptional repressor of lens fiber cell- specific betacrystallin genes. Mol. Cell. Biol. 18: 5579-5586.

EPSTEIN, J., CAI, J., GLASER, T., JEPEAL, L. and MAAS, R. (1994a) Identification of a Pax paired domain recognition sequence and evidence for DNA-dependent conformational changes. J. Biol. Chem. 269: 8355-8361.

EPSTEIN, J. A., GLASER, T., CAI, J., JEPEAL, L., WALTON, D. S. and MAAS, R. L. (1994b). Two independent and interactive DNA-binding subdomains of the Pax6 paired domain are regulated by alternative splicing. Genes Dev. 8: 20222034.

FABER, S. C., DIMANLIG, P., MAKARENKOVA, H. P., SHIRKE, S., KO, K. and LANG, R. A. (2001). Fgf receptor signaling plays a role in lens induction. Development 128: 4425-4438.

FABER, S. C., ROBINSON, M. L., MAKARENKOVA, H. P. and LANG, R. A. (2002). $\mathrm{Bmp}$ signaling is required for development of primary lens fiber cells. Development 129: 3727-3737.

FUJIWARA, M., UCHIDA, T., OSUMI-YAMASHITA, N. and ETO, K. (1994). Uchida rat ( $r$ Sey): a new mutant rat with craniofacial abnormalities resembling those of the mouse Sey mutant. Differentiation 57: 31-38.

FURUTA, Y. and HOGAN, B. L. M. (1998). BMP4 is essential for lens induction in the mouse embryo. Genes Dev. 12: 3764-3775.

GEHRING, W. J. and IKEO, K. (1999). Pax 6: mastering eye morphogenesis and eye evolution. Trends Genet 15: 371-377.

GLASER, T., WALTON, D. S. and MAAS, R. L. (1992). Genomic structure, evolutionary conservation and aniridia mutations in the human PAX6 gene. Nat. Genet. 2: 232-239.

GLASER, T., JEPEAL, L., EDWARDS, J. G., YOUNG, S. R., FAVOR, J., and MAAS, R. L. (1994). PAX6 gene dosage effect in a family with congenital cataracts, aniridia, anophthalmia and central nervous system defects. Nat. Genet. 7: 463471.

GORDON-THOMSON, C., DE IONGH, R. U., HALES, A. M., CHAMBERLAIN, C. G. and MCAVOY, J. W. (1998). Differential cataractogenic potency of TGFbeta1, -beta2, and -beta3 and their expression in the postnatal rat eye. Invest. Ophthalmol. Vis. Sci. 39: 1399-1409.

GRAINGER, R. M. (1992). Embryonic lens induction: shedding light on vertebrate tissue determination. Trends Genet. 8: 349-355.

GRAINGER, R. M., HERRY, J. J. and HENDERSON, R. A. (1988). Reinvestigation of the role of the optic vesicle in embryonic lens induction. Development 102: 517-526.

GRAINGER, R. M., MANNION, J. E., COOK, T. L., JR. and ZYGAR, C. A. (1997). Defining intermediate stages in cell determination: acquisition of a lens-forming bias in head ectoderm during lens determination. Dev. Genet. 20: 246-257.

GRINDLEY, J. C., DAVIDSON, D. R. and HILL, R. E. (1995). The role of Pax-6 in eye and nasal development. Development 121: 1433-1442.

GUMBINER, B. M. (1996). Cell adhesion: the molecular basis of tissue architecture and morphogenesis. Cel/84: 345-357.

HALDER, G., CALLAERTS, P. and GEHRING, W. J. (1995). Induction of ectopic eyes by targeted expression of the eyeless gene in Drosophila. Science 267: 1788-1792.
HAMBURGER, V. and HAMILTON, H. L. (1951). A series of normal stages in the development of the chick embryo. J. Morphol. 88: 49-92.

HANSON, I. and VAN HEYNINGEN, V. (1995). Pax6: more than meets the eye. Trends Genet. 11: 268-272.

HATTA, K. and TAKEICHI, M. (1986). Expression of N-cadherin adhesion molecules associated with early morphogenetic events in chick development. Nature 320: 447-449.

HAYASHI, S., GOTO, K., OKADA, T. S. and KONDOH, H. (1987). Lens-specific enhancer in the third intron regulates expression of the chicken delta 1-crystallin gene. Genes Dev. 1: 818-828.

HENRY, J. J. and GRAINGER, R. M. (1990). Early tissue interactions leading to embryonic lens formation in Xenopus laevis. Dev. Biol. 141: 149-163.

HILL, R. E., FAVOR, J., HOGAN, B. L., TON, C. C., SAUNDERS, G. F., HANSON, I. M., PROSSER, J., JORDAN, T., HASTIE, N. D. and VAN HEYNINGEN, V. (1991). Mouse small eye results from mutations in a paired-like homeoboxcontaining gene [published erratum appears in Nature 1992 Feb 20;355(6362):750]. Nature 35: 522-525.

HIRATA, J., NAKAGOSHI, H., NABESHIMA, Y. and MATSUZAKI, F. (1995). Asymmetric segregation of the homeodomain protein Prospero during Drosophila development. Nature 377: 627-630.

HOLLEMANN, T. and PIELER, T. (1999). Xpitx-1: a homeobox gene expressed during pituitary and cement gland formation of Xenopus embryos. Mech. Dev. 88: 249-252

HYER, J., KUHLMAN, J., AFIF, E. and MIKAWA, T. (2003). Optic cup morphogenesis requires pre-lens ectoderm but not lens differentiation. Dev. Biol. 259: 351 363

JACOBSON, A. G. and SATER, A. K. (1988). Features of embryonic induction. Development 104: 341-359.

KAMACHI, Y., SOCKANATHAN, S., LIU, Q., BREITMAN, M., LOVELL-BADGE, R. and $\mathrm{KONDOH}, \mathrm{H}$. (1995). Involvement of SOX proteins in lens-specific activation of crystallin genes. Embo J. 14: 3510-3519.

KAMACHI, Y., UCHIKAWA, M., COLLIGNON, J., LOVELL-BADGE, R. and $\mathrm{KONDOH}, \mathrm{H}$. (1998). Involvement of Sox1, 2 and 3 in the early and subsequent molecular events of lens induction. Development 125: 2521-2532.

KAMACHI, Y., UCHIKAWA, M., TANOUCHI, A., SEKIDO, R. and KONDOH, H. (2001). Pax6 and SOX2 form a co-DNA-binding partner complex that regulates initiation of lens development. Genes Dev. 15: 1272-1286.

KENYON, K. L., MOODY, S. A. and JAMRICH, M. (1999). A novel fork head gene mediates early steps during Xenopus lens formation. Development 126: 5107 5116.

KING, H.D. (1905). Experimental studies on the eye of the frog embryo. Wilhelm Roux's Arch. Entw. Mech. Org. 19: 85-107.

$\mathrm{KONDOH}, \mathrm{H}$. (1999). Transcription factors for lens development assessed in vivo. Curr. Opin. Genet. Dev. 9: 301-308.

KOSTER, R. W., KUHNLEIN, R. P. and WITTBRODT, J. (2000). Ectopic Sox3 activity elicits sensory placode formation. Mech. Dev. 95: 175-187.

KOZMIK, Z., CZERNY, T. and BUSSLINGER, M. (1997). Alternatively spliced insertions in the paired domain restrict the DNA sequence specificity of Pax6 and Pax8. EMBO J. 16: 6793-6803.

LANG, R. A. (1999). Which factors stimulate lens fiber cell differentiation in vivo? Invest Ophthalmol Vis Sci40: 3075-3078.

LASSAR, A. B., DAVIS, R. L., WRIGHT, W. E., KADESCH, T., MURRE, C., VORONOVA, A., BALTIMORE, D. and WEINTRAUB, H. (1991). Functional activity of myogenic $\mathrm{HLH}$ proteins requires hetero-oligomerization with $\mathrm{E} 12$ / E47-like proteins in vivo. Ce//6: 305-315.

LE, A. C. and MUSIL, L. S. (2001). FGF signaling in chick lens development. Dev. Biol. 233: 394-411.

LEFEBVRE, V., HUANG, W., HARLEY, V. R., GOODFELLOW, P. N. and DE CROMBRUGGHE, B. (1997). SOX9 is a potent activator of the chondrocytespecific enhancer of the pro alpha1 (II) collagen gene. Mol. Cell. Biol. 17:2336-2346.

LEWIS, W. H. (1904). Experimental studies on the development of the eye in amphibia: I. On the origin of the lens, Rana palustris. Am. J. Anat. 3: 505-536.

LENGLER, J., KRAUSZ, E., TOMAREV, S., PRESCOTT, A., QUINLAN, R. A. and GRAW, J. (2001). Antagonistic action of Six3 and Prox1 at the gamma-crystallin promoter. Nucleic Acids Res. 29: 515-526. 
LI, B., PARADIES, N. E. and BRACKENBURY, R. W. (1997). Isolation and characterization of the promoter region of the chicken $\mathrm{N}$ - cadherin gene. Gene 191: 7-13.

LI, H. S., YANG, J. M., JACOBSON, R. D., PASKO, D. and SUNDIN, O. (1994). Pax6 is first expressed in a region of ectoderm anterior to the early neural plate: implications for stepwise determination of the lens. Dev. Biol. 162: 181-194.

LOOSLI, F., KOSTER, R. W., CARL, M., KRONE, A. and WITTBRODT, J. (1998). Six3, a medaka homologue of the Drosophila homeobox gene sine oculis is expressed in the anterior embryonic shield and the developing eye. Mech. Dev. 74: 159-164.

LOVICU, F. J. and OVERBEEK, P. A. (1998). Overlapping effects of different members of the FGF family on lens fiber differentiation in transgenic mice. Development 125: 3365-3377.

MANN, R. S. and AFFOLTER, M. (1998). Hox proteins meet more partners. Curr. Opin. Genet. Dev. 8: 423-429.

MATSUO, I., KURATANI, S., KIMURA, C., TAKEDA, N. and AIZAWA, S. (1995) Mouse Otx2 functions in the formation and patterning of rostral head. Genes Dev. 9: 2646-2658.

MATSUO, I. and YASUDA, K. (1992). The cooperative interaction between two motifs of an enhancer element of the chicken alpha A-crystallin gene, alpha CE1 and alpha CE2, confers lens-specific expression. Nucleic Acids Res. 20: 37013712

MATSUO, T., OSUMI-YAMASHITA, N., NOJI, S., OHUCHI, H., KOYAMA, E., MYOKAI, F., MATSUO, N., TANIGUCHI, S., DOI, H., ISEKI, S. et al., (1993). A mutation in the Pax- 6 gene in rat small eye is associated with impaired migration of midbrain crest cells. Nat. Genet. 3: 299-304.

MCAVOY, J. W. and CHAMBERLAIN, C. G. (1989). Fibroblast growth factor (FGF) induces different responses in lens epithelial cells depending on its concentration. Development 107: 221-228.

MENCL, E. (1903). Ein Fall von beiderseitiger Augenlinsenausbildung wahrend der Abwesenheit von Augenblasen. Wilhelm Roux's Arch. Entw. Mech. Org. 16: 328-339.

MURATA, T., NITTA, M. and YASUDA, K. (1998). Transcription factor CP2 is essential for lens-specific expression of the chicken alphaA-crystallin gene. Genes Cells 3: 443-457.

MUTA, M., KAMACHI, Y., YOSHIMOTO, A., HIGASHI, Y. and KONDOH, H. (2002). Distinct roles of SOX2, Pax6 and Maf transcription factors in the regulation of lens-specific delta1-crystallin enhancer. Genes Cells 7: 791-805.

NISHIGUCHI, S., WOOD, H., KONDOH, H., LOVELL-BADGE, R. and EPISKOPOU, V. (1998). Sox1 directly regulates the gamma-crystallin genes and is essential for lens development in mice. Genes Dev. 12: 776-781.

OCHI, H., OGINO, H., KAGEYAMA, Y. and YASUDA, K. (2003). The stability of the lens-specific Maf protein is regulated by fibroblast growth factor (FGF)/ERK signaling in lens fiber differentiation. J. Biol. Chem. 278: 537-544.

OGINO, H. and YASUDA, K. (1998). Induction of lens differentiation by activation of a bZIP transcription factor, L-Maf. Science 280: 115-118.

OGINO, H. and YASUDA, K. (2000). Sequential activation of transcription factors in lens induction. Dev Growth Differ. 42: 437-448.

OLIVER, G., LOOSLI, F., KOSTER, R., WITTBRODT, J. and GRUSS, P. (1996). Ectopic lens induction in fish in response to the murine homeobox gene Six3. Mech. Dev. 60: 233-239.

OLIVER, G., MAILHOS, A., WEHR, R., COPELAND, N. G., JENKINS, N. A. and GRUSS, P. (1995). Six3, a murine homologue of the sine oculis gene, demarcates the most anterior border of the developing neural plate and is expressed during eye development. Development 121: 4045-4055.

PIATIGORSKY, J. (1992). Lens crystallins. Innovation associated with changes in gene regulation. J. Biol. Chem. 267: 4277-4280.

PIATIGORSKY, J. (2003). Crystallin genes: specialization by changes in gene regulation may precede gene duplication. J. Struct. Funct. Genomics 3: 131137.

PORTER, F. D., DRAGO, J., XU, Y., CHEEMA, S. S., WASSIF, C., HUANG, S. P., LEE, E., GRINBERG, A., MASSALAS, J. S., BODINE, D. et al., (1997). Lhx2, a LIM homeobox gene, is required for eye, forebrain, and definitive erythrocyte development. Development 124: 2935-2944.
PUSCHEL, A. W., GRUSS, P. and WESTERFIELD, M. (1992). Sequence and expression pattern of pax- 6 are highly conserved between zebrafish and mice. Development 114: 643-651.

REZA, H. M., OGINO, H. and YASUDA, K. (2002). L-Maf, a downstream target of Pax6, is essential for chick lens development. Mech. Dev. 116: 61-73.

REZA, H. M. and YASUDA, K. (2004). Roles of Maf family proteins in lens development. Dev. Dyn. 229: 440-448.

RICHARDSON, J., CVEKL, A. and WISTOW, G. (1995). Pax-6 is essential for lensspecific expression of zeta-crystallin. Proc. Natl. Acad. Sci. USA92: 4676-4680.

ROBINSON, M. L., OVERBEEK, P. A., VERRAN, D. J., GRIZZLE, W. E., STOCKARD C. R., FRIESEL, R., MACIAG, T. and THOMPSON, J. A. (1995). Extracellular FGF-1 acts as a lens differentiation factor in transgenic mice. Development 121 : 505-514.

SCHULZ, M. W., CHAMBERLAIN, C. G., DE IONGH, R. U. and MCAVOY, J. W (1993). Acidic and basic FGF in ocular media and lens: implications for lens polarity and growth patterns. Development 118: 117-126.

SERVETNICK, M. and GRAINGER, R. M. (1991). Changes in neural and lens competence in Xenopus ectoderm: evidence for an autonomous developmental timer. Development 112: 177-188.

SHIMADA, N., AYA-MURATA, T., REZA, H. M. and YASUDA, K. (2003). Cooperative action between L-Maf and Sox2 on delta-crystallin gene expression during chick lens development. Mech. Dev. 120: 455-465.

SINGH, S., MISHRA, R., ARANGO, N. A., DENG, J. M., BEHRINGER, R. R. and SAUNDERS, G. F. (2002). Iris hypoplasia in mice that lack the alternatively spliced Pax6(5a) isoform. Proc. Natl. Acad. Sci. USA 99: 6812-6815.

SPEMANN, H. (1901). Uber Korrelationen in die entwickelung des Auges. Verh Anat. Ges. 15: 61-79.

SRINIVASAN, Y., LOVICU, F. J. and OVERBEEK, P. A. (1998). Lens-specific expression of transforming growth factor beta1 in transgenic mice causes anterior subcapsular cataracts. J. Clin. Invest. 101: 625-634.

TOMAREV, S. I., SUNDIN, O., BANERJEE-BASU, S., DUNCAN, M. K., YANG, J M. and PIATIGORSKY, J. (1996). Chicken homeobox gene Prox 1 related to Drosophila prospero is expressed in the developing lens and retina. Dev. Dyn. 206: 354-367

TROUSSE, F., ESTEVE, P. and BOVOLENTA, P. (2001). Bmp4 mediates apoptotic cell death in the developing chick eye. J. Neurosci. 21: 1292-1301.

VAN HEYNINGEN, V. and WILLIAMSON, K. A. (2002). PAX6 in sensory development. Hum. Mol. Genet. 11: 1161-1167.

VAN RENS, G. L., DE JONG, W. W. and BLOEMENDAL, H. (1991). One member of the gamma-crystallin gene family, gamma s, is expressed in birds. Exp. Eye Res. 53: 135-138.

VOGEL-HOPKER, A., MOMOSE, T., ROHRER, H., YASUDA, K., ISHIHARA, L. and RAPAPORT, D. H. (2000). Multiple functions of fibroblast growth factor-8 (FGF-8) in chick eye development. Mech. Dev. 9: 25-36.

WALTHER, C. and GRUSS, P. (1991). Pax-6, a murine paired box gene, is expressed in the developing CNS. Development 113: 1435-1449.

WALTHER, C., GUENET, J. L., SIMON, D., DEUTSCH, U., JOSTES, B., GOULDING, M. D., PLACHOV, D., BALLING, R. and GRUSS, P. (1991). Pax: a murine multigene family of paired box-containing genes. Genomics 11: 424-434

WAWERSIK, S., PURCELL, P., RAUCHMAN, M., DUDLEY, A. T., ROBERTSON E. J. and MAAS, R. (1999). BMP7 acts in murine lens placode development. Dev. Biol. 207: 176-188.

WEINTRAUB, H., DAVIS, R., LOCKSHON, D. and LASSAR, A. (1990). MyoD binds cooperatively to two sites in a target enhancer sequence: occupancy of two sites is required for activation. Proc. Natl. Acad. Sci. USA 87: 5623-5627.

WEST-MAYS, J. A., ZHANG, J., NOTTOLI, T., HAGOPIAN-DONALDSON, S., LIBBY, D., STRISSEL, K. J. and WILLIAMS, T. (1999). AP-2alpha transcription factor is required for early morphogenesis of the lens vesicle. Dev. Biol. 206: 4662

WIGLE, J. T., CHOWDHURY, K., GRUSS, P. and OLIVER, G. (1999). Prox1 function is crucial for mouse lens-fibre elongation. Nat. Genet. 21: 318-322.

WISTOW, G. J. and PIATIGORSKY, J. (1988). Lens crystallins: the evolution and expression of proteins for a highly specialized tissue. Annu. Rev. Biochem. 57: 479-504. 
YAGI, T. and TAKEICHI, M. (2000). Cadherin superfamily genes: functions, genomic organization, and neurologic diversity. Genes Dev. 14: 1169-1180.

YAMADA, R., MIZUTANI-KOSEKI, Y., HASEGAWA, T., OSUMI, N., KOSEKI, H. and TAKAHASHI, N. (2003). Cell-autonomous involvement of Mab21l1 is essential for lens placode development. Development 130: 1759-1770.

YOSHIDA, T. and YASUDA, K. (2002). Characterization of the chicken L-Maf, MafB and c-Maf in crystallin gene regulation and lens differentiation. Genes Cel/s 7: 693-706.

YUAN, H., CORBI, N., BASILICO, C. and DAILEY, L. (1995). Developmentalspecific activity of the FGF-4 enhancer requires the synergistic action of Sox2 and Oct-3. Genes Dev. 9: 2635-2645.

ZHANG, X., FRIEDMAN, A., HEANEY, S., PURCELL, P. and MAAS, R. L. (2002) Meis homeoproteins directly regulate $\mathrm{Pax} 6$ during vertebrate lens morphogenesis. Genes Dev. 16: 2097-2107.

ZHU, C. C., DYER, M. A., UCHIKAWA, M., KONDOH, H., LAGUTIN, O. V. and OLIVER, G. (2002). Six3-mediated auto repression and eye development requires its interaction with members of the Groucho-related family of corepressors. Development 129: 2835-2849.

ZYGAR, C. A., COOK, T. L. and GRAINGER, R. M., JR. (1998). Gene activation during early stages of lens induction in Xenopus. Development 125: 3509-3519. 